\title{
Review Article Naturally Occurring Anthraquinones: Chemistry and
Therapeutic Potential in Autoimmune Diabetes
}

\author{
Shih-Chang Chien, ${ }^{1}$ Yueh-Chen Wu, ${ }^{2}$ Zeng-Weng Chen, ${ }^{3}$ and Wen-Chin Yang ${ }^{2,3,4,5,6,7}$ \\ ${ }^{1}$ Department of Forestry, National Chung-Hsing University, Taichung 402, Taiwan \\ ${ }^{2}$ Agricultural Biotechnology Research Center, Academia Sinica, No. 128, Academia Sinica Road, Sec. 2, Nankang, Taipei 115, Taiwan \\ ${ }^{3}$ Animal Technology Institute, Chunan 350, Taiwan \\ ${ }^{4}$ Department of Life Sciences, National Chung-Hsing University, Taichung 402, Taiwan \\ ${ }^{5}$ Institute of Biotechnology, National Taiwan University, Taipei 106, Taiwan \\ ${ }^{6}$ Department of Aquaculture, National Taiwan Ocean University, Keelung 202, Taiwan \\ ${ }^{7}$ Institute of Pharmacology, Yang-Ming University, Taipei 112, Taiwan
}

Correspondence should be addressed to Wen-Chin Yang; wcyang@gate.sinica.edu.tw

Received 10 June 2014; Accepted 10 August 2014

Academic Editor: Cicero L. T. Chang

Copyright (C) 2015 Shih-Chang Chien et al. This is an open access article distributed under the Creative Commons Attribution License, which permits unrestricted use, distribution, and reproduction in any medium, provided the original work is properly cited.

\begin{abstract}
Anthraquinones are a class of aromatic compounds with a 9,10-dioxoanthracene core. So far, 79 naturally occurring anthraquinones have been identified which include emodin, physcion, cascarin, catenarin, and rhein. A large body of literature has demonstrated that the naturally occurring anthraquinones possess a broad spectrum of bioactivities, such as cathartic, anticancer, antiinflammatory, antimicrobial, diuretic, vasorelaxing, and phytoestrogen activities, suggesting their possible clinical application in many diseases. Despite the advances that have been made in understanding the chemistry and biology of the anthraquinones in recent years, research into their mechanisms of action and therapeutic potential in autoimmune disorders is still at an early stage. In this paper, we briefly introduce the etiology of autoimmune diabetes, an autoimmune disorder that affects as many as 10 million worldwide, and the role of chemotaxis in autoimmune diabetes. We then outline the chemical structure and biological properties of the naturally occurring anthraquinones and their derivatives with an emphasis on recent findings about their immune regulation. We discuss the structure and activity relationship, mode of action, and therapeutic potential of the anthraquinones in autoimmune diabetes, including a new strategy for the use of the anthraquinones in autoimmune diabetes.
\end{abstract}

\section{Autoimmune Diabetes}

1.1. Etiology and Therapies for Autoimmune Diabetes. Autoimmune diabetes (AID) is a life-threatening metabolic disease that is initiated and progresses through a complex interplay of environmental, genetic, and immune factors. As a result, insulin-producing $\beta$-cells are destroyed by leukocytes leading to insufficient/deficient insulin that fails to maintain blood glucose homeostasis, and lethal macro- and microvascular complications ensue. In 2013, the International Diabetes Federation (IDF) estimated that some 79,000 children under 15 years develop AID annually worldwide [1].

In patients and animal models of AID, at disease onset, leukocytes infiltrate into the pancreatic islets [2]. Among the leukocytes, $\mathrm{T}$ lymphocytes are the main players in AID although B lymphocytes, dendritic cells, macrophages, and NK cells are also implicated in this invasion, a condition termed insulitis $[3,4]$. This invasion contributes to a gradual loss of pancreatic $\beta$-cells, leading to insulin insufficiency/ deficiency and then hyperglycemia, two hallmarks of AID [5].

So far, insulin injection is the only way to control AID; however, it fails to cure the disease and can only ameliorate its complications. Therefore, discovery of novel and effective approaches to cure AID is necessary. Immune therapy, replacement therapy using insulin, $\beta$-cells, islets, and pancreas, and combination therapy have all been tested to prevent and treat AID (Figure 1) [6]. Migration of leukocytes during diabetes development is viewed as a critical target through which to interfere with the disease onset and progression. From the immune perspective, chemokines and 


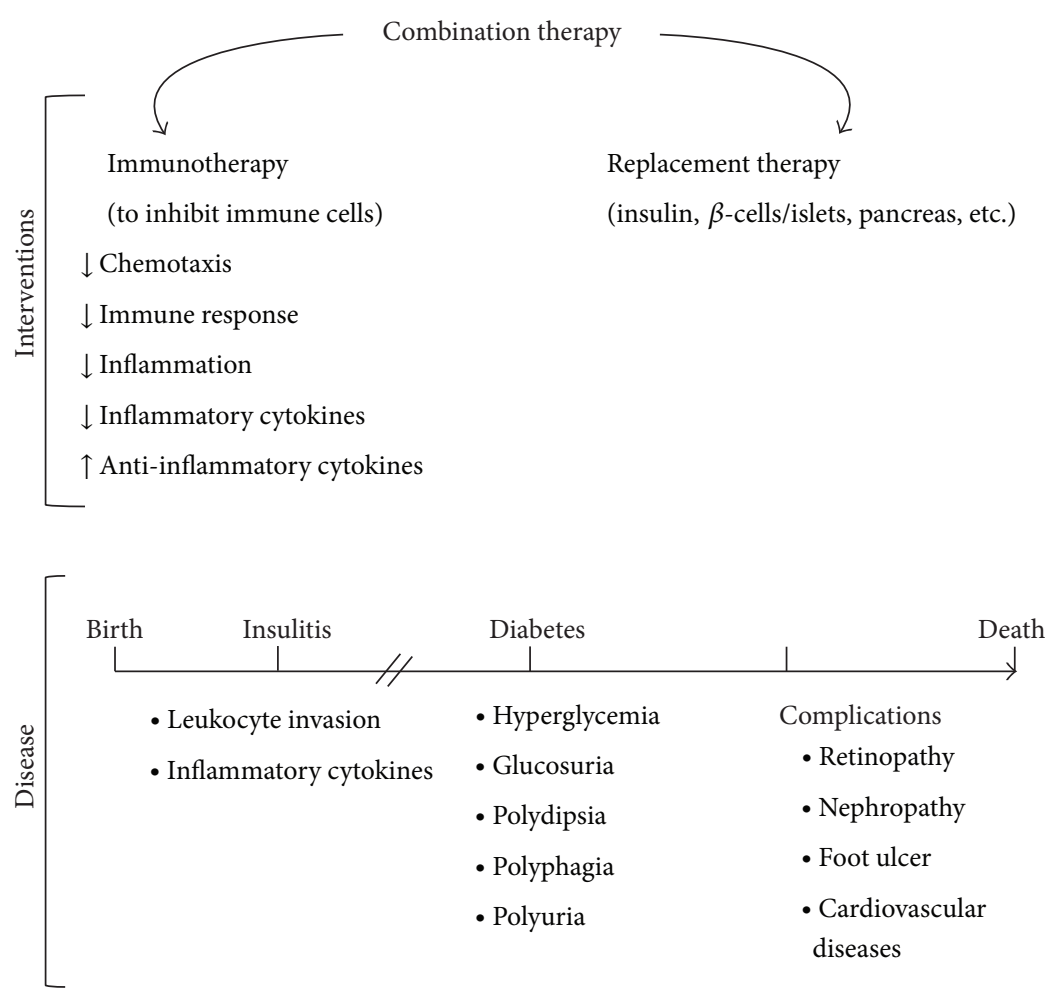

FIgURE 1: AID development and intervention. During AID onset, leukocytes start to invade pancreatic islets, a condition termed insulitis, followed by diabetes. Diabetes is characterized by hyperglycemia, insulin insufficiency/deficiency, and glucosuria. Polydipsia, polyphagia, and polyuria are found in diabetic patients. Diabetic complications such as retinopathy, nephropathy, foot ulcers, and cardiovascular disease result in fatality of patients. Immunotherapy, replacement therapy, and combinations of both are common approaches to treat AID.

their pathways are attractive targets for intervention and may hold the key to stopping insulitis and, thus, delay or prevent AID [7-10]. Preservation of functional $\beta$-cells is equally crucial for curing AID [11]. This topic has been reviewed elsewhere [12], however, and is not within the scope of this paper.

1.2. Chemotaxis and Its Mechanism in Leukocytes. In mammals, 23 chemokine receptors and over 50 chemokines have been discovered (Figure 2) [13]. They function in health and disease in roles such as cell recruitment during embryogenesis, leukocyte trafficking, helper $\mathrm{T}$ cell differentiation, angiogenesis, HIV infection, sepsis, atherosclerosis, inflammation, immune disorders, and cancer metastasis [14]. One of the most important functions of chemokine/chemokine receptors is to direct the migration of leukocytes from the venous system to sites of inflammation. They play an essential role in inflammation and, as a consequence, inflammatory diseases such as autoimmune diseases and cancers [15]. Structurally speaking, chemokine receptors belong to a family of 7helix transmembrane G protein-coupled receptors (GPCRs). Upon chemokine engagement, chemokine receptors initiate the binding of the G $\alpha$ subunit to guanosine triphosphate and the dissociation of the $\mathrm{G} \alpha$ subunit from the G $\beta \gamma$ subunit. This activates protein tyrosine kinases, mitogen-activated protein (MAP) kinases, and phospholipase C. Secondary messengers, inositol triphosphate and diacylglycerol, which are converted from phosphatidylinositol by phospholipase C, induce cellular calcium influx and translocation/activation of protein kinase $\mathrm{C}$, respectively. The above biochemical cascades lead to cell chemotaxis and other cell functions (Figure 4(a)) [16]. Hence, chemokines/chemokine receptors have been proposed as drug targets for inflammatory diseases [14, 1719]. For instance, the first FDA approved CXCR4 antagonist, plerixafor/AMD3100, is used to mobilize hematopoietic stem cells, which are collected for use in stem cell graft in patients with hematological cancers. Plerixafor was initially developed to interfere with SDF-1/CXCR4 interaction and shows promise for HIV infection, cancers, and autoimmune diseases such as rheumatoid arthritis [20]. However, this drug is expensive because of the difficulty in its total synthesis. There is, therefore, a demand for the discovery of new CXCR4 antagonists that are both cost-effective and potent.

Since $\mathrm{T}$ cells and other leukocytes are thought to be essential players in AID $[3,21]$, interference with chemokine receptors in leukocytes could be a promising approach for treating insulitis and AID prophylaxis. CXCR4 is expressed in all the leukocytes including naïve T cells [22]. CCR5 is preferentially expressed in activated $\mathrm{T}$ cells and macrophages [23-25]. And CCR3 and CCR4 are implicated in Th2 cells whereas CXCR3 and CCR5 are associated with Th1 cells [14]. On the flip side, genetic studies further showed that deficiency in CXCR3 and CCR2 accelerated AID in NOD mice $[26,27]$. In contrast, CCR5 ablation delayed AID [27], which was contradictory to one publication indicating 


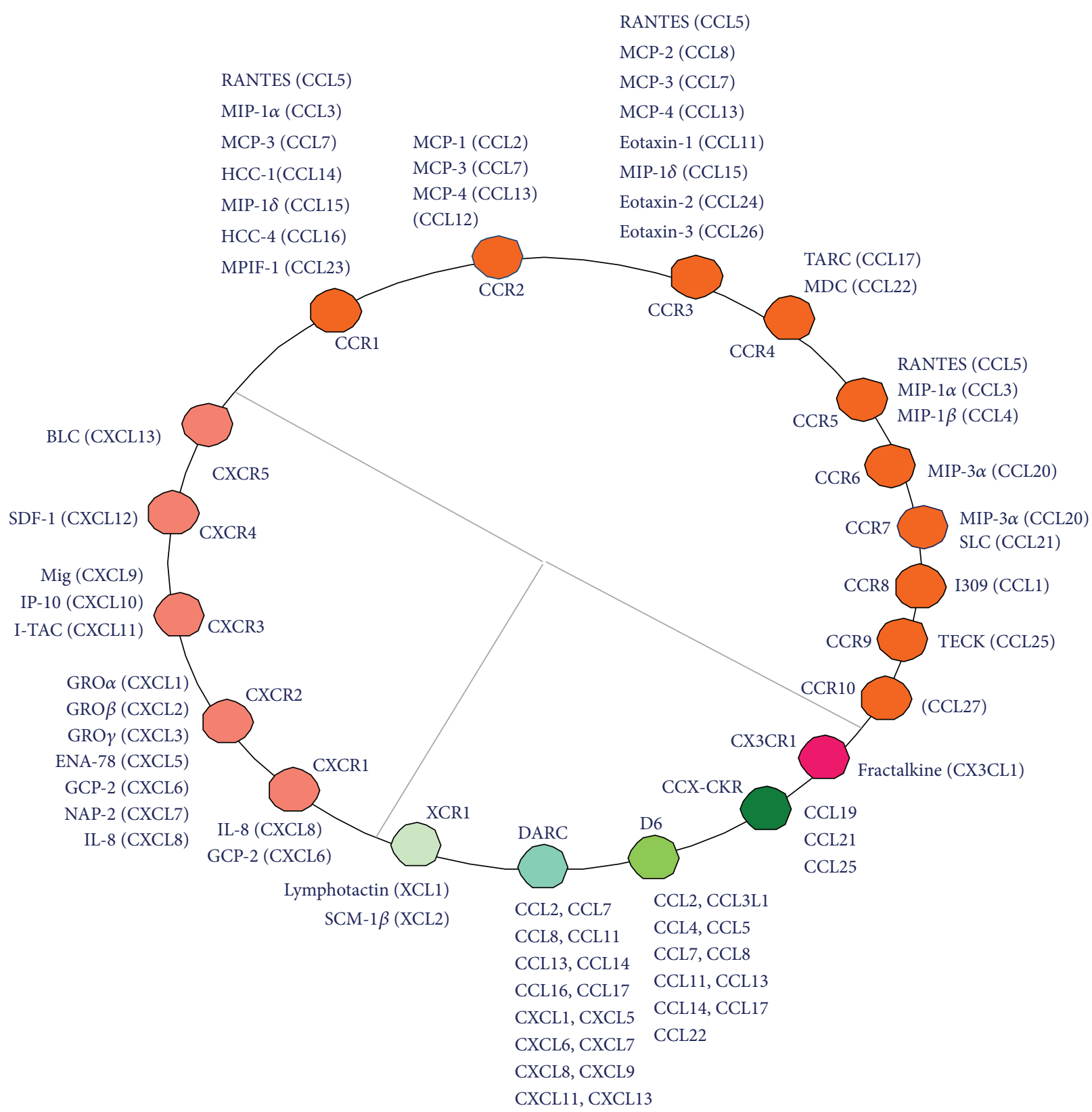

FIGURE 2: Chemokines and their cognate receptors. Twenty-three chemokine receptors and their natural ligands are classified into CCR, CXCR, and other categories.

that CCR5 positively regulated AID [28]. Anti-CXCL10 was reported to delay AID in NOD mice, implying that CXCR3 may accelerate AID [29]. Overexpression of D6 in pancreatic islets reduced AID in NOD mice [30]. Overexpression of CCL2, a natural ligand for DARC, D6, and CCR2, in the pancreas reduced AID in NOD mice [31], which is consistent with a negative regulation of AID by CCR2, D6, and DACR. Of them, the impact of DARC in AID is unclear.

1.3. Mouse Models of AID. Animal models are indispensable for dissecting pathogenesis and for preclinical trials in AID despite some difference between animal models and patients. The animal models include streptozotocin- (STZ-) treated mice, nonobese diabetic (NOD) mice, Biobreeding (BB) rats, Long Evans Tokushima Lean (LETL) rats, New Zealand white rabbits, Chinese hamsters, Keeshond dogs, and Celebes black apes [12].

\section{Naturally Occurring Anthraquinones}

2.1. Chemical Structure and Biosynthesis of Naturally Occurring Anthraquinones. Naturally occurring anthraquinones (NOAQs) are a group of secondary metabolites structurally related to 9,10-dioxoanthracene (also known as anthracene 9,10-diones) and their glycosides (Table 1 and Figure 4). Currently, there are 79 known NOAQs [32], which were isolated 


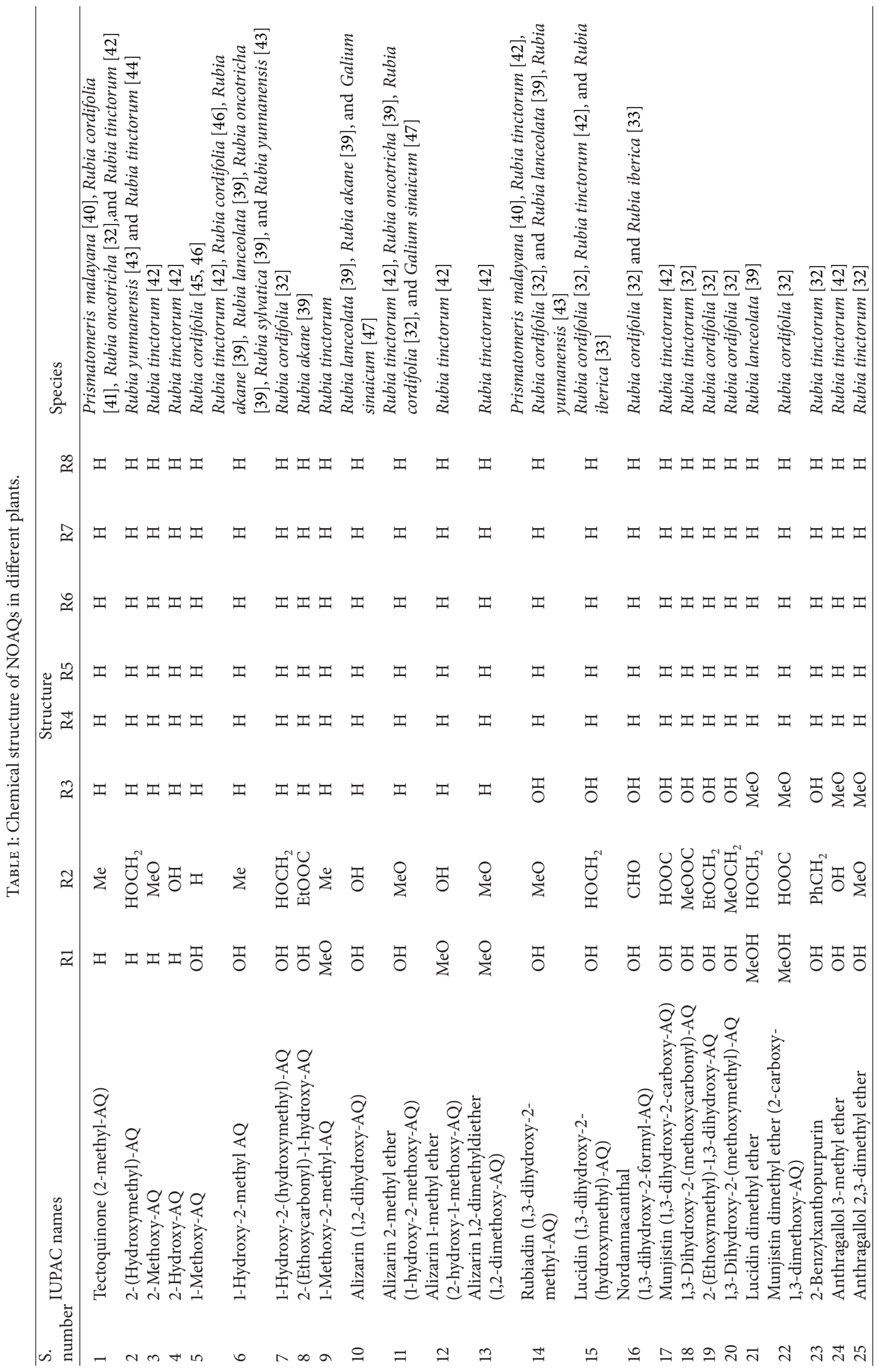




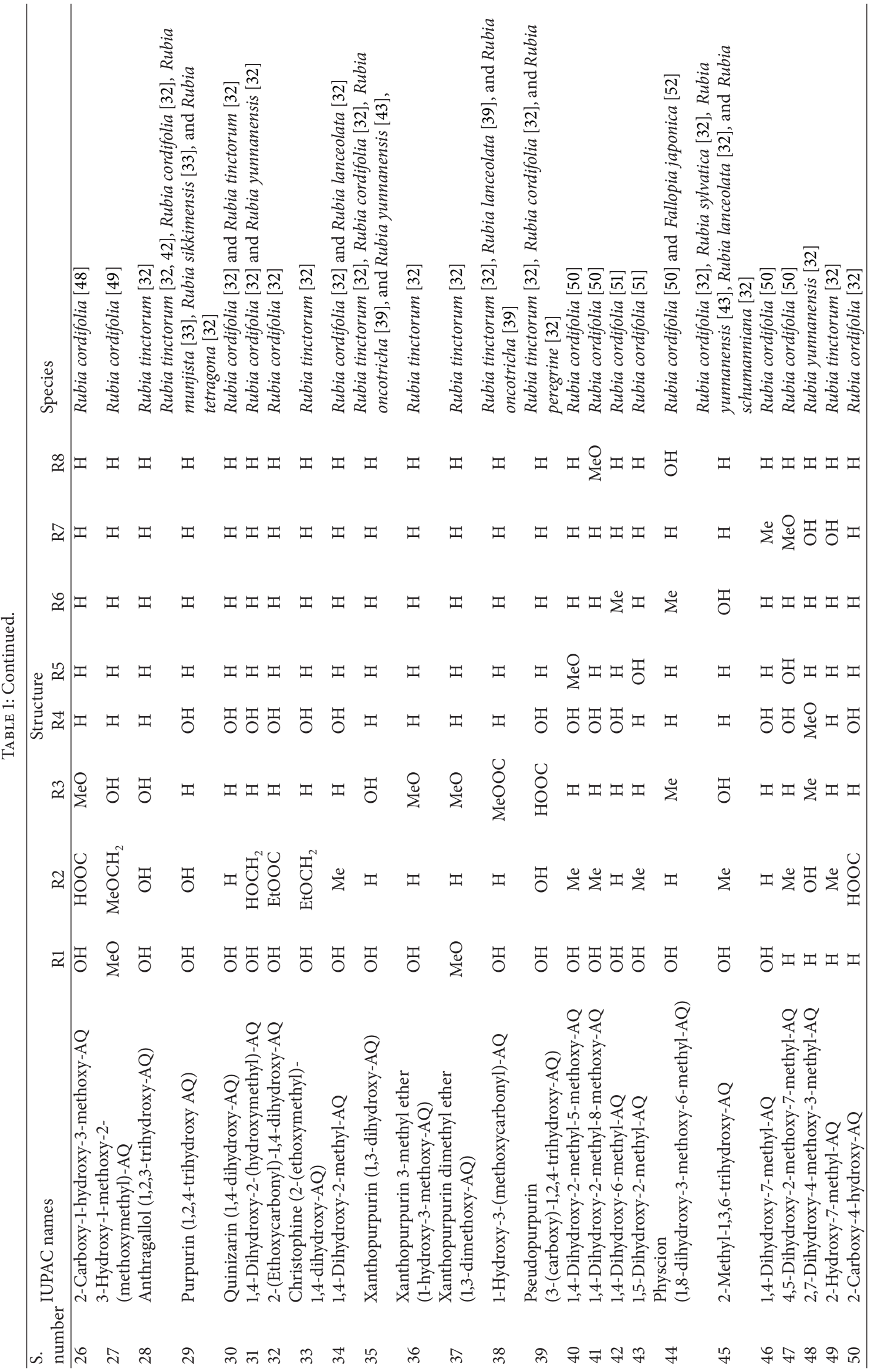




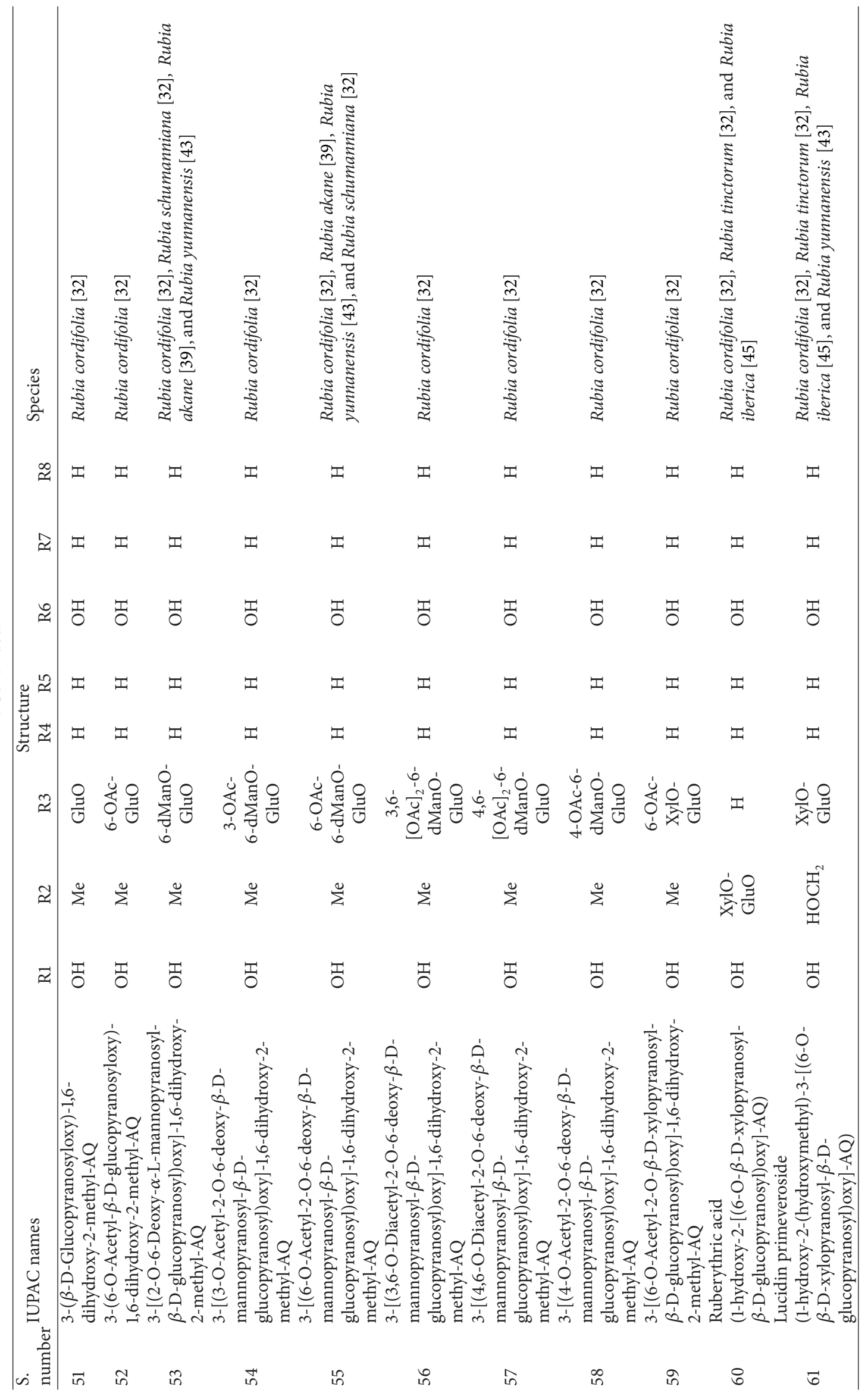




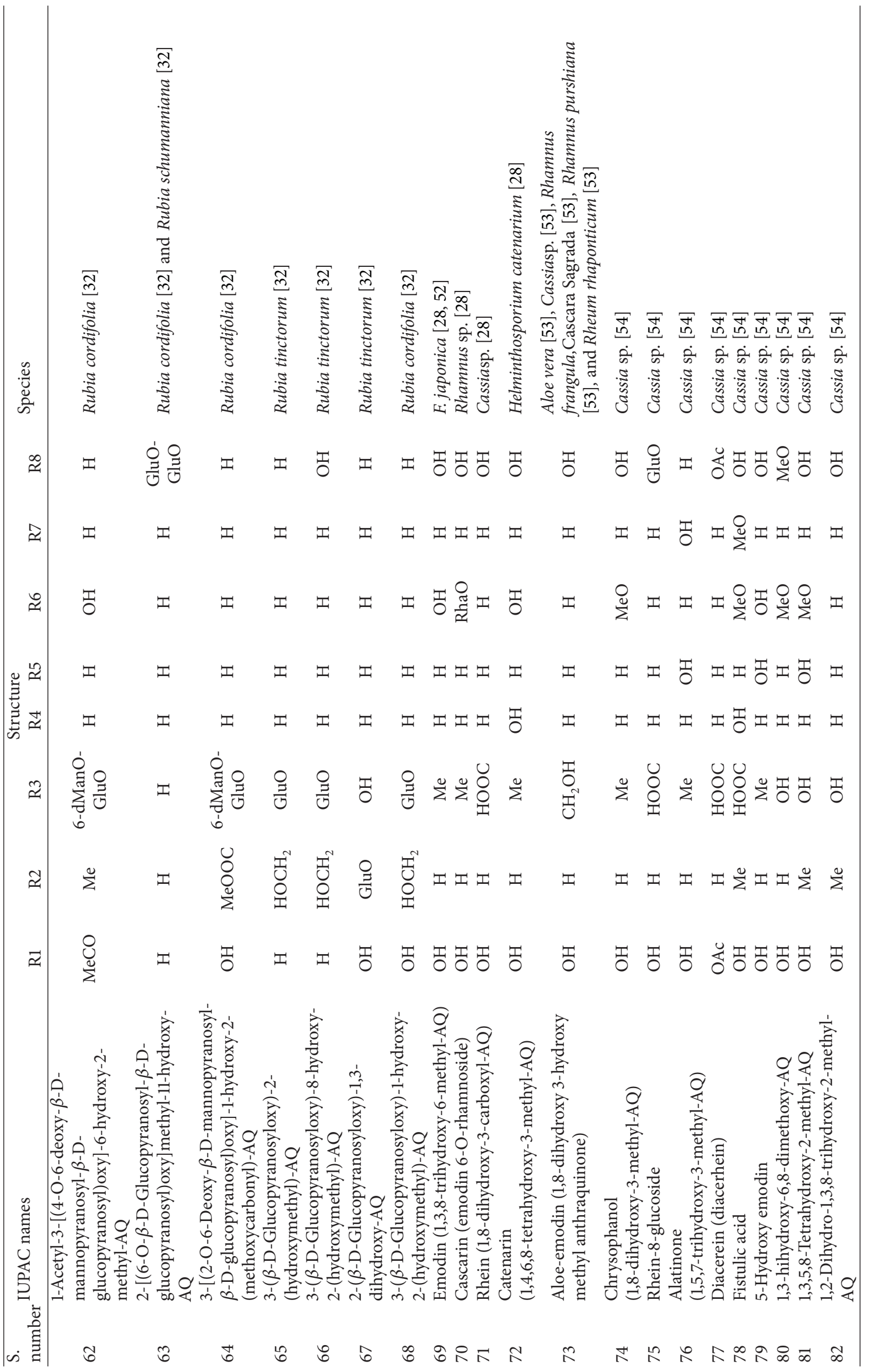




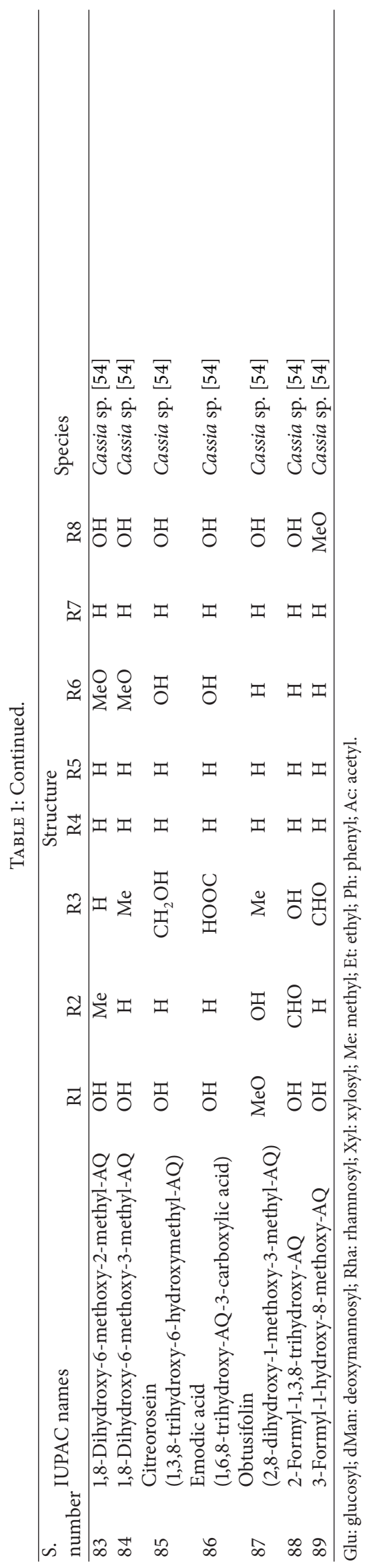




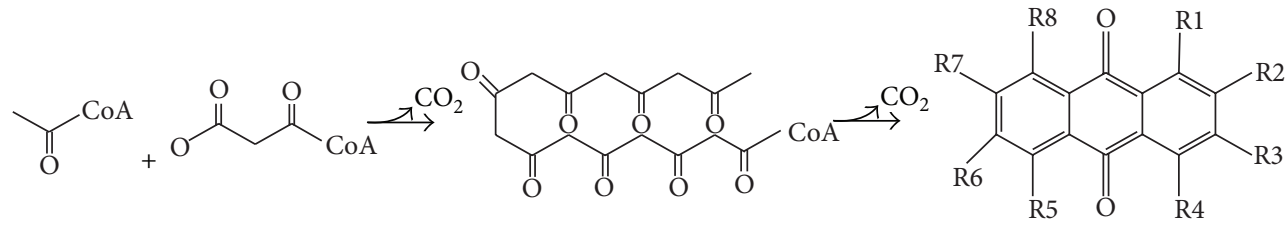

(a)<smiles>CC1=C(C(=O)O)CC(O)C(O)C1O</smiles><smiles>CCCC(=O)c1ccccc1C(=O)O</smiles><smiles>O=C(O)CCC(=O)C(=O)O</smiles><smiles>[R6]c1c([R2])c([R1])c2c(c1[R8])C(=O)c1c([R1])c([R3])c([R2])c([R1])c1C2=O</smiles><smiles>CCC(C)/C(C)=C/CC1=CC(O)c2cc(C)ccc2C1O</smiles><smiles>CC(O)(CO)CC(=O)O</smiles>

(b)

FIGURE 3: Schema outlining the biosynthesis of anthraquinones. Anthraquinones can be synthesized from acetyl CoA and malonyl CoA via the polyketide pathway (a), or from shikimic acid (b) via the shikimate pathway.

from lichens, fungi, or higher medicinal plants (e.g., Polygonaceae, Rhamnaceae, Rubiaceae, Fabaceae, and Xanthorrhoeaceae) [32-38]. Although their biosynthetic pathways are not yet fully clear, NOAQs can be biosynthesized from the polyketide (Figure 3(a)) or shikimate (Figure 3(b)) pathway as described in Figure 3 [39]. They can be formed either by the cyclization of linear octa- $\beta$-ketoacyl CoA intermediates from the addition of one acetyl CoA to three malonyl CoA or by the addition of succinoylbenzoic acid, resulting from shikimic acid and $\alpha$-ketoglutaric acid, to mevalonic acid.

2.2. Mechanism of Action of NOAQs in AID. NOAQs have widespread applications throughout medicine as well as in industry. Medicinally speaking, they show a wide spectrum of bioactivities. Most of them are best known as laxative compounds for constipation. Apart from laxative activity, emodin, the most studied anthraquinone, has been reported to have cathartic, anti-inflammatory, anticancer, antimicrobial, diuretic, DNA-binding, and vasorelaxant activities [2, 55-57]. In addition, emodin, physcion, anthraglycoside B, citreorosein, and emodin 8-O- $\beta$-D-glucopyranoside were found to have laxative, anti-inflammatory, and other activities [58-60]. Emodin and physcion are kinase and tyrosinase inhibitors [61-63] and also show cytotoxicity against cancer cells [55, 64]. In addition, emodin, citreorosein, and emodin 8-O- $\beta$-D-glucopyranoside showed phytoestrogen activity $[60,65,66]$. Further, anthraglycoside $B$ has been used to treat acute hepatitis and leukocyte reduction [59].

Recently, NOAQs have been explored for their potential in AID intervention. In one study, Fallopia japonica, an anti-inflammatory herb rich in anthraquinones, was tested for AID. NOD mice received intraperitoneal injection of the F. japonica crude extract at $40 \mu \mathrm{g} / \mathrm{kg}$ BW, 3 times a week from 4 to 30 weeks (prevention) or from 9 to 30 weeks (therapy). Twelve-week-old NOD mice started to develop AID, and $100 \%$ of NOD mice aged 24 weeks and above developed AID. Remarkably, $86 \%$ and $80 \%$ of 30 -week-old NOD mice treated with F. japonica crude extract did not develop AID [67]. Consistent with AID incidence, the crude extract delayed and reduced the invasion of leukocytes into the pancreatic islets [67]. Using a chemotaxis-based fractionation and isolation approach, two anthraquinones, emodin and physcion, were isolated and identified from this plant [67]. Moreover, in vitro study showed that emodin and physcion exhibited a reduction in CXCR4-mediated migration of Jurkat cells, a human $\mathrm{T}$ cell line [67]. A negative control, resveratrol, had no effect on the CXCR4-implicated migration. This reduction in migration involved the inhibition of MAPKs, ERK 1/2, and MAPKK, MEK 1/2 [67]. Accordingly, at doses from $4 \mathrm{mg} / \mathrm{kg}$ to $40 \mathrm{mg} / \mathrm{kg}$, emodin and physcion dose-dependently reduced insulitis and AID in NOD mice [67].

In another study, Shen and colleagues showed that catenarin, cascarin, emodin, and rhein inhibited CXR4mediated chemotaxis in Jurkat $\mathrm{T}$ cells [28]. The half maximal inhibitory concentrations $\left(\mathrm{IC}_{50}\right)$ of the CXCR4-mediated migration for catenarin, cascarin, emodin, and rhein were $0.18 \mu \mathrm{g} / \mathrm{mL}, 0.3 \mu \mathrm{g} / \mathrm{mL}, 0.3 \mu \mathrm{g} / \mathrm{mL}$, and $2.7 \mu \mathrm{g} / \mathrm{mL}$, respectively [28]. The $\mathrm{IC}_{50}$ of the CCR5-mediated migration for catenarin, emodin, cascarin, and rhein were $0.5 \mu \mathrm{g} / \mathrm{mL}$, $0.75 \mu \mathrm{g} / \mathrm{mL}, 1.46 \mu \mathrm{g} / \mathrm{mL}$, and $2.5 \mu \mathrm{g} / \mathrm{mL}$, respectively [28]. 


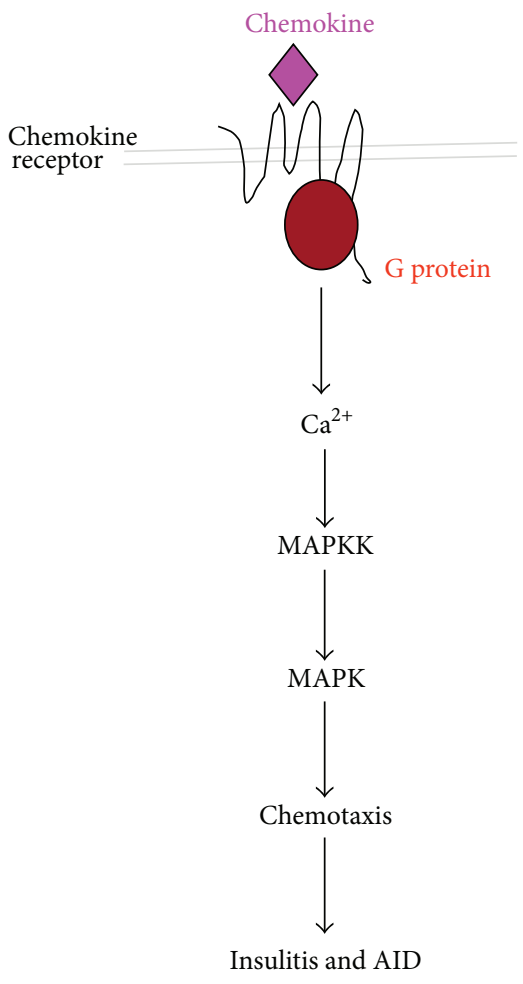

(a)

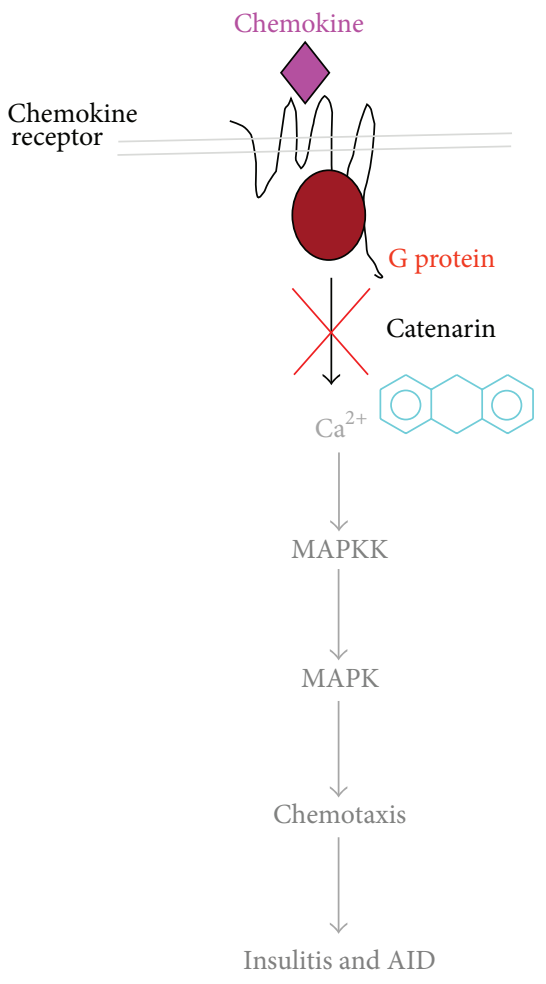

(b)

FIGURE 4: Mode of action of catenarin and other anthraquinones for AID. (a) Upon chemokine binding, a chemokine receptor is activated and induces $G$ protein activation. A cascade of calcium mobilization and activation/phosphorylation of MAPKK/MAPK pathways leads to chemotaxis of leukocytes and, subsequently, insulitis and diabetes. (b) Catenarin and probably other anthraquinones inhibit leukocyte migration mediated by CCR5 and CXCR4 via the inactivation of MAPKs (p38 and JNK), MKKs (MKK6 and MKK7), and calcium mobilization. As a result, anthraquinones can suppress insulitis and diabetes.

Catenarin had higher antichemotactic activity than the other anthraquinones. This activity appears to relate to the number of hydroxyl groups at R5 and R7 in the anthraquinones, revealing a structure-activity relationship of hydroxyl groups in anthraquinones. The $\mu$-slide assays, used to follow the trafficking direction, also demonstrated that, at a dose of $0.5 \mu \mathrm{g} / \mathrm{mL}$, catenarin could completely stop cell movement towards the specific chemokine gradient [28]. These data suggest that the potential of the anthraquinones to inhibit chemotaxis depends on chemokine properties [28]. Further, in an in vivo study, $100 \%$ of NOD mice developed AID at the age of 24 weeks or beyond. The diabetic incidence of NOD mice treated with catenarin at $0.4,4$, and $20 \mathrm{mg} / \mathrm{kg}$, 3 times a week, from 4 to 30 weeks, was $80 \%, 70 \%, 30 \%$, and $0 \%$. NOD mice treated with $20 \mathrm{mg} / \mathrm{kg}$ catenarin had normal blood glucose $(<200 \mathrm{mg} / \mathrm{dL})$ and $\mathrm{Hb}_{\mathrm{Alc}}(<4 \%)$, intact islet structure, and very few leukocytes $\left(\mathrm{CD} 4^{+} \mathrm{T}, \mathrm{CD} 8^{+} \mathrm{T}\right.$, dendritic cells, macrophages, and NK and $\mathrm{B}$ cells) in the pancreatic islets [28]. Flow cytometry showed that catenarin did not influence the expression of chemokine receptors on the cell surface, excluding the possibility that catenarin (and, probably, other anthraquinones) work(s) at the level of the chemokine receptors [28]. In addition, catenarin reduced calcium mobilization in Jurkat cells whilst being exposed to CXCR4 ligand, SDF-1, and CCR4 ligand, MIP-1 [28].
Further, catenarin inhibited JNK and p38 but not ERK $1 / 2$ and, in turn, their upstream regulators, MKK 6/7 [28]. These mechanistic studies concluded that catenarin and/or its derivatives exerted antidiabetic action via chemotactic regulation of leukocytes involving the $\mathrm{Ca}^{2+} / \mathrm{MAPKK} / \mathrm{MAPK}$ pathways (Figure 4(b) and Table 2). Of note, catenarin has the highest antichemotactic activity, followed in decreasing order by emodin, cascarin, and rhein. Interestingly, catenarin has two hydroxyl groups at R4 and R6 in its anthraquinone ring. Emodin has only one hydroxyl group at R6. Cascarin and rhein have no hydroxyl groups at R4 and R6. This activity seems to be related to the number of hydroxyl groups at R4 and R6 in anthraquinones as described in Figure 4(a) and Table 1 .

Diacerein is a commercial drug commonly utilized to treat human osteoarthritis. It was developed from its prodrug rhein. Very interestingly, diacerein can be used to treat AID in NOD mice [68] akin to its prodrug, rhein [28]. Overall, the data supported the notion that rhein in its stable form, albeit at low efficacy, may be a better pharmaceutical intervention than the other anthraquinones with higher activity.

There is lack of information about the impact of the other chemokines/chemokine receptors in AID. We showed that NOAQs can target CXCR4 and CCR5 pathways [28, 67]. CXCR3, CCR2, CXCL10, CCL2, and D6 were reported 
TABLE 2: NOAQs with antidiabetic activities.

\begin{tabular}{|c|c|c|c|c|}
\hline S. number & Name & Classification & Molecular formula & Biological activities \\
\hline 72 & Catenarin & Anthraquinone & $\mathrm{C}_{15} \mathrm{H}_{10} \mathrm{O}_{6}$ & Antichemotactic [28] and antidiabetic [28] \\
\hline 69 & Emodin & Anthraquinone & $\mathrm{C}_{15} \mathrm{H}_{10} \mathrm{O}_{5}$ & Antichemotactic [67] and antidiabetic [67] \\
\hline 44 & Physcion & Anthraquinone & $\mathrm{C}_{16} \mathrm{H}_{12} \mathrm{O}_{5}$ & Antichemotactic [28] \\
\hline 70 & Cascarin & Anthraquinone & $\mathrm{C}_{21} \mathrm{H}_{20} \mathrm{O}_{9}$ & Antichemotactic [28] \\
\hline 71 & Rhein & Anthraquinone & $\mathrm{C}_{15} \mathrm{H}_{8} \mathrm{O}_{6}$ & Antichemotactic [28] \\
\hline 77 & Diacerein & Anthraquinone & $\mathrm{C}_{19} \mathrm{H}_{12} \mathrm{O}_{8}$ & Antiosteoarthritic [68] and antidiabetic [28] \\
\hline
\end{tabular}

to control diabetes development [26, 27, 29-31]. Whether NOAQs target their pathways remains unclear.

\section{Toxicology}

Emodin, one of the most well-studied anthraquinones, is frequently present in laxative herbs. Furthermore, emodin is reported to be effective against cancer, constipation, inflammation, microbes, and peptic ulcers [69]. However, its safety and effectiveness in naturopathic treatment have not been approved by the U.S. Food and Drug Administration (FDA). Side effects of emodin, and probably other anthraquinones, include potential carcinogenesis, nausea, diarrhea, and renal failure. Two anthraquinone-type agents, danthron, a drug for constipation, and diacerein, an anti-inflammatory drug for osteoarthritis, were developed and approved by the U.S. FDA $[68,70]$. However, danthron was withdrawn by the FDA in 1999 due to the risk of carcinogenesis [70]. Therefore, clinical use of the anthraquinones should be considered cautiously.

\section{Conclusions and Perspectives}

Several NOAQs show anti-inflammatory activity. Among them, cascarin, catenarin, rhein, physcion, and emodin suppress the chemotactic activity of leukocytes at the insulitis stage of AID development. They suppress chemokinemediated leukocyte migration towards pancreatic islets leading to a decline in AID development. This suppression involves anthraquinone-mediated inhibition of MAPKK/ MAPK pathway. An antiosteoarthritic anthraquinone drug, diacerein, has been shown to prevent AID in a NOD model, suggesting that the antichemotactic activity of the risk-free anthraquinones can likely be exploited for AID and other inflammatory diseases.

$\begin{array}{ll}\text { Abbreviations } \\ \text { AID: } & \text { Autoimmune diabetes } \\ \text { NOAQ: } & \text { Naturally occurring anthraquinone } \\ \text { NOD mice: } & \text { Nonobese diabetic mice } \\ \text { GPCR: } & \text { G protein-coupled receptor } \\ \text { MAPK: } & \text { Mitogen-activated protein kinase } \\ \text { MAPKK: } & \text { Mitogen-activated protein kinase } \\ \text { IC } 50 & \text { Half maximal inhibitory concentration } \\ \text { STZ: } & \text { Streptozotocin } \\ \text { BB rats: } & \text { Biobreeding rats } \\ \text { LETL rats: } & \text { Long Evans Tokushima Lean rats. }\end{array}$

\section{Conflict of Interests}

The authors declare that there is no conflict of interests regarding the publication of this paper.

\section{Authors' Contribution}

Shih-Chang Chien and Yueh-Chen Wu contributed equally to this work.

\section{Acknowledgment}

The authors thank the authors of the articles cited in this paper.

\section{References}

[1] International Diabetes Foundation Committee, "IDF DIABETES ATLAS," 2013.

[2] T. Cha, L. Qiu, C. Chen, Y. Wen, and M. Hung, "Emodin downregulates androgen receptor and inhibits prostate cancer cell growth," Cancer Research, vol. 65, no. 6, pp. 2287-2295, 2005.

[3] L. A. O'Reilly, P. R. Hutchings, P. R. Crocker et al., "Characterization of pancreatic islet cell infiltrates in NOD mice: effect of cell transfer and transgene expression," European Journal of Immunology, vol. 21, no. 5, pp. 1171-1180, 1991.

[4] M. Lodoen, K. Ogasawara, J. A. Hamerman et al., "NKG2Dmediated natural killer cell protection against cytomegalovirus is impaired by viral gp 40 modulation of retinoic acid early inducible 1 gene molecules," Journal of Experimental Medicine, vol. 197, no. 10, pp. 1245-1253, 2003.

[5] D. L. Eizirik, M. L. Colli, and F. Ortis, "The role of inflammation in insulitis and B-cell loss in type 1 diabetes," Nature Reviews Endocrinology, vol. 5, no. 4, pp. 219-226, 2009.

[6] D. Bresson and M. von Herrath, "Moving towards efficient therapies in type 1 diabetes: to combine or not to combine?" Autoimmunity Reviews, vol. 6, no. 5, pp. 315-322, 2007.

[7] M. A. Atkinson and S. Brian Wilson, "Fatal attraction: chemokines and type 1 diabetes," The Journal of Clinical Investigation, vol. 110, no. 11, pp. 1611-1613, 2002.

[8] L. M. Bradley, V. C. Asensio, L. Schioetz et al., "Islet-specific Th1, but not Th2, cells secrete multiple chemokines and promote rapid induction of autoimmune diabetes," Journal of Immunology, vol. 162, no. 5, pp. 2511-2520, 1999.

[9] M. J. Cameron, G. A. Arreaza, M. Grattan et al., "Differential expression of CC chemokines and the CCR5 receptor in the pancreas is associated with progression to type I diabetes," Journal of Immunology, vol. 165, no. 2, pp. 1102-1110, 2000. 
[10] C. Meagher, S. Sharif, S. Hussain, M. J. Cameron, G. A. Arreaza, and T. L. Delovitch, "Cytokines and chemokines in the pathogenesis of murine Type 1 diabetes," Advances in Experimental Medicine and Biology, vol. 520, pp. 133-158, 2003.

[11] A. Vetere, A. Choudhary, S. M. Burns, and B. K. Wagner, "Targeting the pancreatic $\beta$-cell to treat diabetes," Nature Reviews Drug Discovery, vol. 13, pp. 278-289, 2014.

[12] C. L. Chang, Y. C. Chen, H. M. Chen, N. S. Yang, and W. C. Yang, "Natural cures for type 1 diabetes: a review of phytochemicals, biological actions, and clinical potential," Current Medicinal Chemistry, vol. 20, no. 7, pp. 899-907, 2013.

[13] S. J. Allen, S. E. Crown, and T. M. Handel, "Chemokine: receptor structure, interactions, and antagonism," Annual Review of Immunology, vol. 25, pp. 787-820, 2007.

[14] A. E. I. Proudfoot, "Chemokine receptors: multifaceted therapeutic targets," Nature Reviews Immunology, vol. 2, no. 2, pp. 106-115, 2002.

[15] T. Jin, X. Xu, and D. Hereld, "Chemotaxis, chemokine receptors and human disease," Cytokine, vol. 44, no. 1, pp. 1-8, 2008.

[16] C. Murdoch and A. Finn, "Chemokine receptors and their role in inflammation and infectious diseases," Blood, vol. 95, no. 10, pp. 3032-3043, 2000.

[17] J. E. Pease and T. J. Williams, "The attraction of chemokines as a target for specific anti-inflammatory therapy," British Journal of Pharmacology, vol. 147, no. 1, pp. S212-S221, 2006.

[18] J. E. Turner, O. M. Steinmetz, R. A. Stahl, and U. Panzer, "Targeting of Thl-associated chemokine receptors CXCR3 and CCR5 as therapeutic strategy for inflammatory diseases," MiniReviews in Medicinal Chemistry, vol. 7, no. 11, pp. 1089-1096, 2007.

[19] U. Christen, "Chemokines as drug targets in type 1 diabetes," Endocrine, Metabolic and Immune Disorders_Drug Targets, vol. 7, no. 1, pp. 7-12, 2007.

[20] E. de Clercq, "The AMD3100 story: the path to the discovery of a stem cell mobilizer (Mozobil)," Biochemical Pharmacology, vol. 77, no. 11, pp. 1655-1664, 2009.

[21] H. Toyoda and B. Formby, "Contribution of T cells to the development of autoimmune diabetes in the NOD mouse model," BioEssays, vol. 20, no. 9, pp. 750-757, 1998.

[22] S. K. Bromley, T. R. Mempel, and A. D. Luster, "Orchestrating the orchestrators: chemokines in control of T cell traffic," Nature Immunology, vol. 9, no. 9, pp. 970-980, 2008.

[23] E. Aboumrad, A. M. Madec, and C. Thivolet, "The CXCR4/CXCL12 (SDF-1) signalling pathway protects nonobese diabetic mouse from autoimmune diabetes," Clinical \& Experimental Immunology, vol. 148, no. 3, pp. 432-439, 2007.

[24] C. Carvalho-Pinto, M. I. García, L. Gómez et al., "Leukocyte attraction through the CCR5 receptor controls progress from insulitis to diabetes in non-obese diabetic mice," European Journal of Immunology, vol. 34, no. 2, pp. 548-557, 2004.

[25] C. Hagemann, R. Patel, and J. L. Blank, "MEKK3 interacts with the PA28 $\gamma$ regulatory subunit of the proteasome," Biochemical Journal, vol. 373, no. 1, pp. 71-79, 2003.

[26] Y. Yamada, Y. Okubo, A. Shimada et al., "Acceleration of diabetes development in CXC chemokine receptor 3 (CXCR3)deficient NOD mice," Diabetologia, vol. 55, no. 8, pp. 2238-2245, 2012.

[27] M. Solomon, B. Balasa, and N. Sarvetnick, "CCR2 and CCR5 chemokine receptors differentially influence the development of autoimmune diabetes in the NOD mouse," Autoimmunity, vol. 43 , no. 2 , pp. 156-163, 2010.
[28] M. Y. Shen, Y. P. Lin, B. C. Yang et al., "Catenarin prevents type 1 diabetes in nonobese diabetic mice via inhibition of leukocyte migration involving the MEK6/p38 and MEK7/JNK pathways," Evidence-Based Complementary and Alternative Medicine, vol. 2012, Article ID 982396, 13 pages, 2012.

[29] J. Morimoto, H. Yoneyama, A. Shimada et al., "CXC chemokine ligand 10 neutralization suppresses the occurrence of diabetes in nonobese diabetic mice through enhanced $\beta$ cell proliferation without affecting insulitis," The Journal of Immunology, vol. 173, no. 11, pp. 7017-7024, 2004.

[30] G. J. Lin, S. H. Huang, Y. W. Chen et al., “Transgenic expression of murine chemokine decoy receptor D6 by islets reveals the role of inflammatory CC chemokines in the development of autoimmune diabetes in NOD mice," Diabetologia, vol. 54, no. 7, pp. 1777-1787, 2011.

[31] M. A. Kriegel, C. Rathinam, and R. A. Flavell, "Pancreatic islet expression of chemokine CCL2 suppresses autoimmune diabetes via tolerogenic CD11c+ CD11b+ dendritic cells," Proceedings of the National Academy of Sciences of the United States of America, vol. 109, no. 9, pp. 3457-3462, 2012.

[32] R. Singh and S. M. Chauhan, "9,10-Anthraquinones and other biologically active compounds from the genus Rubia," Chemistry \& Biodiversity, vol. 1, no. 9, pp. 1241-1264, 2004.

[33] R. A. Muzychkina, Natural Anthraquinones, PHASIS Publishing House, Moscow, Russia, 1998.

[34] A. Mathey, P. Spiteller, and W. Steglich, "Draculone, a new anthraquinone pigment from the tropical lichen Melanotheca cruenta," Zeitschrift fur Naturforschung C: Journal of Biosciences, vol. 57, no. 7-8, pp. 565-567, 2002.

[35] V. Ivanova, R. Schlegel, and U. Grafe, "2-Methoxy-4,5,7trihydroxy-anthraquinone, a new lichen metabolite produced by Xanthoria parietina," Die Pharmazie, vol. 55, no. 10, pp. 785786, 2000.

[36] S. Kanokmedhakul, K. Kanokmedhakul, N. Phonkerd, K. Soytong, P. Kongsaeree, and A. Suksamrarn, "Antimycobacterial anthraquinone-chromanone compound and diketopiperazine alkaloid from the fungus Chaetomium globosum KMITLN0802," Planta Medica, vol. 68, no. 9, pp. 834-836, 2002.

[37] Y. Yang, Y. M. Yan, W. Wei et al., "Anthraquinone derivatives from Rumex plants and endophytic Aspergillus fumigatus and their effects on diabetic nephropathy," Bioorganic and Medicinal Chemistry Letters, vol. 23, no. 13, pp. 3905-3909, 2013.

[38] J. Westendorf, B. Poginsky, H. Marquardt, and L. Kraus, "Possible carcinogenicity of anthraquinone-containing medical plants," Planta Medica, vol. 54, p. 562, 1988.

[39] Y. Han, R. van der Heijden, A. W. M. Lefeber, C. Erkelens, and R. Verpoorte, "Biosynthesis of anthraquinones in cell cultures of Cinchona "Robusta" proceeds via the methylerythritol 4phosphate pathway," Phytochemistry, vol. 59, no. 1, pp. 45-55, 2002.

[40] P. Tuntiwachwuttikul, Y. Butsuri, P. Sukkoet, U. Prawat, and W. C. Taylor, "Anthraquinones from the roots of Prismatomeris malayana," Natural Product Research, vol. 22, no. 11, pp. 962968, 2008.

[41] A. Koyama, K. Sasou, H. Nakao et al., "Pulmonary intralobar sequestration accompanied by aneurysm of an anomalous arterial supply," Internal Medicine, vol. 31, no. 7, pp. 946-950, 1992.

[42] Y. Kawasaki, Y. Goda, and K. Yoshihira, "The mutagenic constituents of Rubia tinctorum," Chemical \& Pharmaceutical Bulletin, vol. 40, no. 6, pp. 1504-1509, 1992. 
[43] M. J. Liou and T. S. Wu, "Triterpenoids from Rubia yunnanensis," Journal of Natural Products, vol. 65, no. 9, pp. 1283-1287, 2002.

[44] G. C. H. Derksen, H. A. G. Niederländer, and T. A. Van Beek, "Analysis of anthraquinones in Rubia tinctorum L. by liquid chromatography coupled with diode-array UV and mass spectrometric detection," Journal of Chromatography A, vol. 978, no. 1-2, pp. 119-127, 2002.

[45] V. V. Murti and T. R. Seshadri, "Naturally occurring less common amino acids of possible nutritional interest and their simpler derivatives," Nutrition abstracts and reviews, vol. 37, no. 3, pp. 677-693, 1967.

[46] S. X. Wang, H. M. Hua, L. J. Wu, X. Li, and T. R. Zhu, "Studies on anthraquinones from the roots of rubia cordifolia," Acta Pharmaceutica Sinica, vol. 27, no. 10, pp. 743-747, 1992.

[47] A. A. El-Gamal, K. Takeya, H. Itokawa et al., "Anthraquinones from the polar fractions of Galium sinaicum," Phytochemistry, vol. 42, no. 4, pp. 1149-1155, 1996.

[48] A. M. Vidal-Tessier, P. Delaveau, and B. Champion, "New quinones from the roots of Rubia cordifolia L," Annales Pharmaceutiques Francaises, vol. 44, no. 2, pp. 117-122, 1986.

[49] A. M. Vidal-Tessier, P. Delaveau, and B. Champion, "New anthraquinones of Rubia cordifolia L.," Annales Pharmaceutiques Francaises, vol. 45, no. 3, pp. 261-267, 1987.

[50] C. Dosseh, A. M. Tessier, and P. Delaveau, "Rubia cordifolia roots. II: new quinones," Planta Medica, vol. 43, no. 2, pp. 141$147,1981$.

[51] C. Dosseh, A. M. Tessier, and P. Delaveau, "New quinones in Rubia cordifolia L. Roots, III," Planta Medica, vol. 43, pp. 360366, 1981.

[52] K. Xiao, L. Xuan, Y. Xu, D. Bai, and D. Zhong, "Constituents from Polygonum cuspidatum," Chemical and Pharmaceutical Bulletin, vol. 50, no. 5, pp. 605-608, 2002.

[53] R. Chen, J. Zhang, Y. Hu, S. Wang, M. Chen, and Y. Wang, "Potential antineoplastic effects of Aloe-emodin: a comprehensive review," The American Journal of Chinese Medicine, vol. 42, pp. 275-288, 2014.

[54] H. Dave and L. Ledwani, "A review on anthraquinones isolated from Cassia species and their applications," Indian Journal of Natural Products and Resources, vol. 3, no. 3, pp. 291-319, 2012.

[55] S. Lin, W. Lai, C. Ho et al., "Eniodin induces apoptosis of human tongue squamous cancer SCC-4 cells through reactive oxygen species and mitochondria-dependent pathways," Anticancer Research, vol. 29, no. 1, pp. 327-335, 2009.

[56] L. C. Chang, H. M. Sheu, Y. S. Huang, T. R. Tsai, and K. W. Kuo, "A novel function of emodin: enhancement of the nucleotide excision repair of UV- and cisplatin-induced DNA damage in human cells," Biochemical Pharmacology, vol. 58, no. 1, pp. 4957, 1999.

[57] Y. Ding, L. Zhao, H. Mei et al., "Exploration of Emodin to treat alpha-naphthylisothiocyanate-induced cholestatic hepatitis via anti-inflammatory pathway," European Journal of Pharmacology, vol. 590, no. 1-3, pp. 377-386, 2008.

[58] Y. L. Leu, T. L. Hwang, J. W. Hu, and J. Y. Fang, "Anthraquinones from Polygonum cuspidatum as tyrosinase inhibitors for dermal use," Phytotherapy Research, vol. 22, no. 4, pp. 552-556, 2008.

[59] X. Chu, A. Sun, and R. Liu, "Preparative isolation and purification of five compounds from the Chinese medicinal herb Polygonum cuspidatum Sieb. et Zucc by high-speed countercurrent chromatography," Journal of Chromatography A, vol. 1097, no. 1-2, pp. 33-39, 2005.
[60] H. Matsuda, H. Shimoda, T. Morikawa, and M. Yoshikawa, "Phytoestrogens from the roots of Polygonum cuspidatum (Polygonaceae): structure-requirement of hydroxyanthraquinones for estrogenic activity," Bioorganic and Medicinal Chemistry Letters, vol. 11, no. 14, pp. 1839-1842, 2001.

[61] G. S. Jayatilake, H. Jayasuriya, E.-. Lee et al., "Kinase inhibitors from Polygonum cuspidatum," Journal of Natural Products, vol. 56, no. 10, pp. 1805-1810, 1993.

[62] H. Jayasuriya, N. M. Koonchanok, R. L. Geahlen, J. L. McLaughlin, and C. J. Chang, "Emodin, a protein tyrosine kinase inhibitor from Polygonum cuspidatum," Journal of Natural Products, vol. 55, no. 5, pp. 696-698, 1992.

[63] L. Zhang, Y. K. Lau, L. Xi et al., “Tyrosine kinase inhibitors, emodin and its derivative repress HER-2/neu-induced cellular transformation and metastasis-associated properties," Oncogene, vol. 16, no. 22, pp. 2855-2863, 1998.

[64] M. Bachmann, P. Blaser, J. Luthy, and C. Schlatter, "Toxicity and mutagenicity of anthraquinones from Aspergillus chevalieri," Journal of Environmental Pathology, Toxicology and Oncology, vol. 11, no. 2, pp. 49-52, 1992.

[65] C. Zhang, X. Wang, X. Zhang, Y. Zhang, H. Xiao, and X. Liang, "Bioassay-guided separation of citreorosein and other oestrogenic compounds from Polygonum cuspidatum," Phytotherapy Research, vol. 23, no. 5, pp. 740-741, 2009.

[66] R. Bösch, U. Friederich, W. K. Lutz, E. Brocker, M. Bachmann, and C. Schlatter, "Investigations on DNA binding in rat liver and in Salmonella and on mutagenicity in the Ames test by emodin, a natural anthraquinone," Mutation Research, vol. 188, no. 3, pp. 161-168, 1987.

[67] M. Y. Shen, Y. J. Liu, M. J. Don et al., "Combined phytochemistry and chemotaxis assays for identification and mechanistic analysis of anti-inflammatory phytochemicals in Fallopia japonica," PLoS ONE, vol. 6, no. 11, Article ID e27480, 2011.

[68] M. Nguyen, M. Dougados, L. Berdah, and B. Amor, "Diacerhein in the treatment of osteoarthritis of the hip," Arthritis and Rheumatism, vol. 37, no. 4, pp. 529-536, 1994.

[69] G. Srinivas, S. Babykutty, P. P. Sathiadevan, and P. Srinivas, "Molecular mechanism of emodin action: transition from laxative ingredient to an antitumor agent," Medicinal Research Reviews, vol. 27, no. 5, pp. 591-608, 2007.

[70] "Danthron," in Report on Carcinogens, pp. 128-129, Department of Health and Human Services, National Toxicology Program, 12th edition, 2011. 


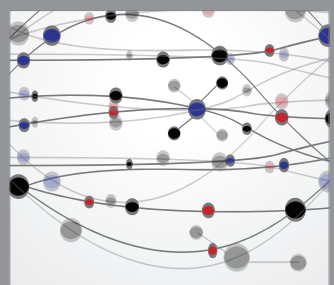

The Scientific World Journal
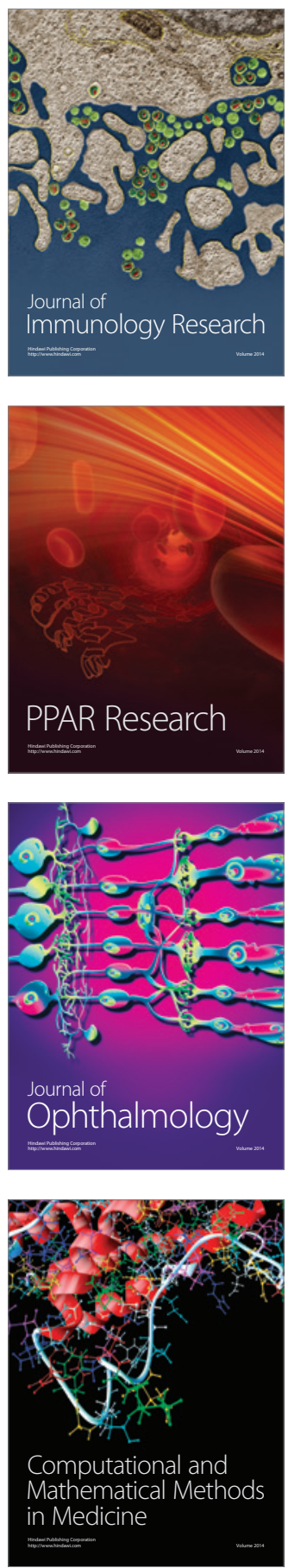

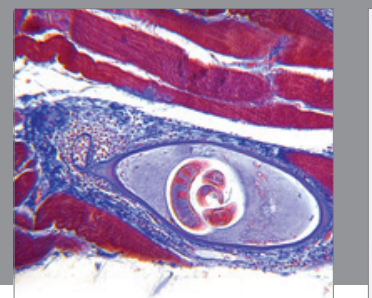

Gastroenterology

Research and Practice
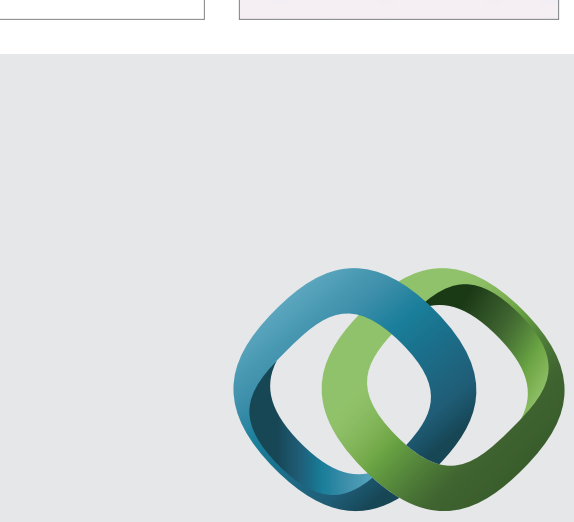

\section{Hindawi}

Submit your manuscripts at

http://www.hindawi.com
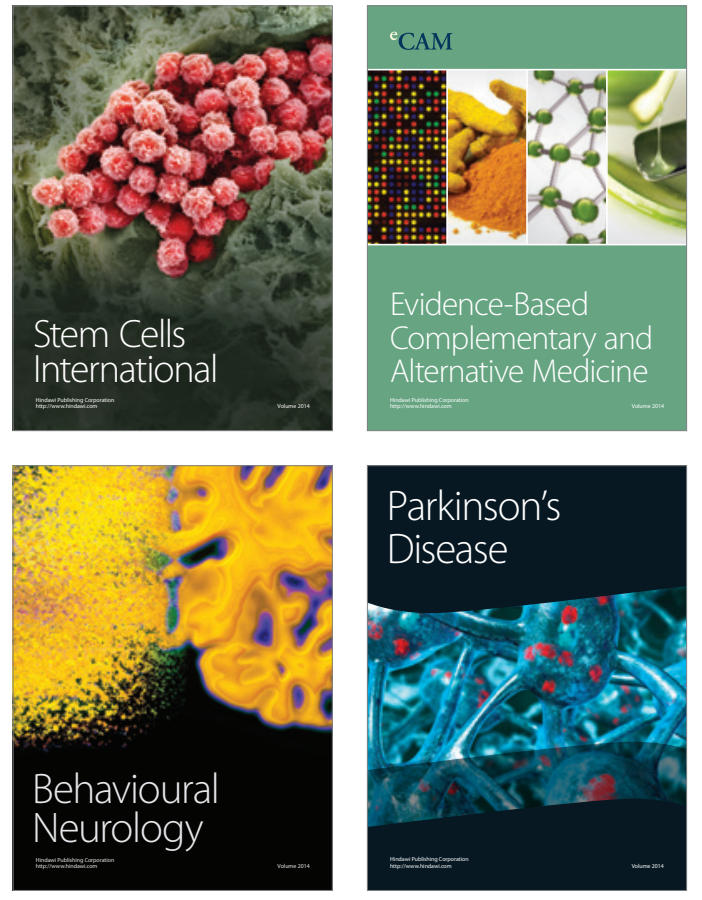
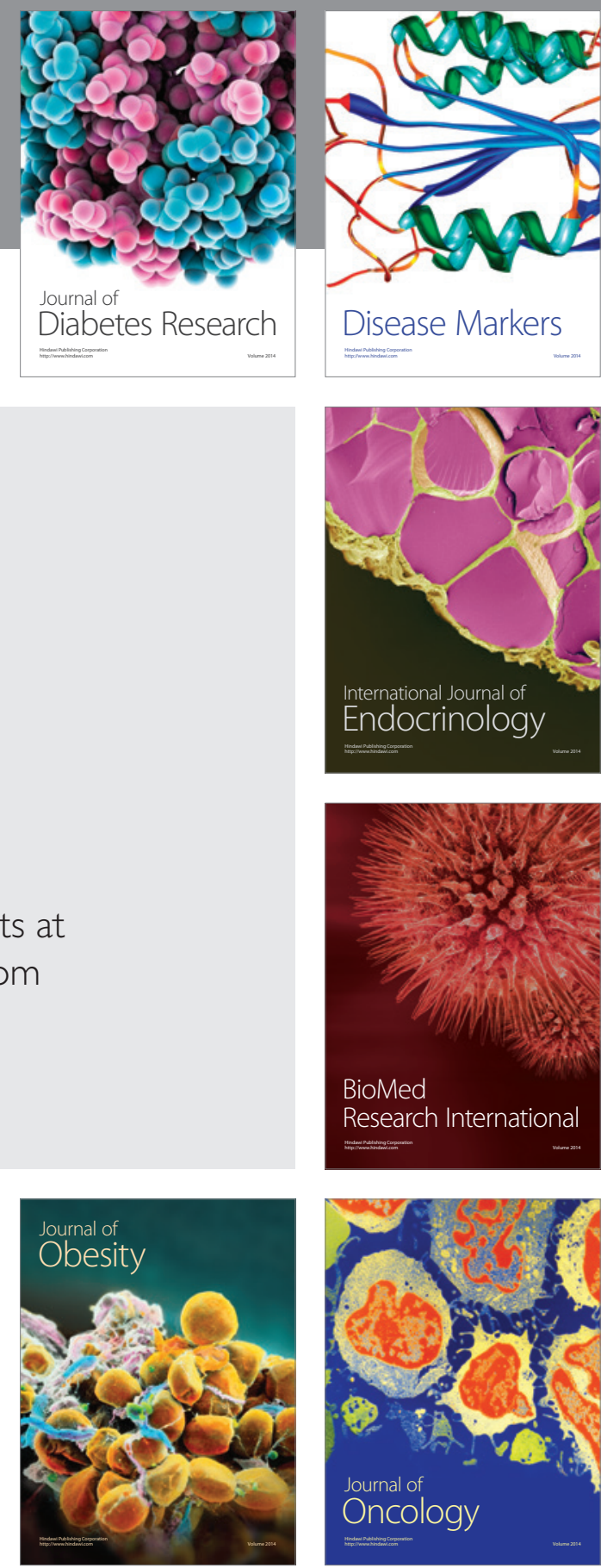

Disease Markers
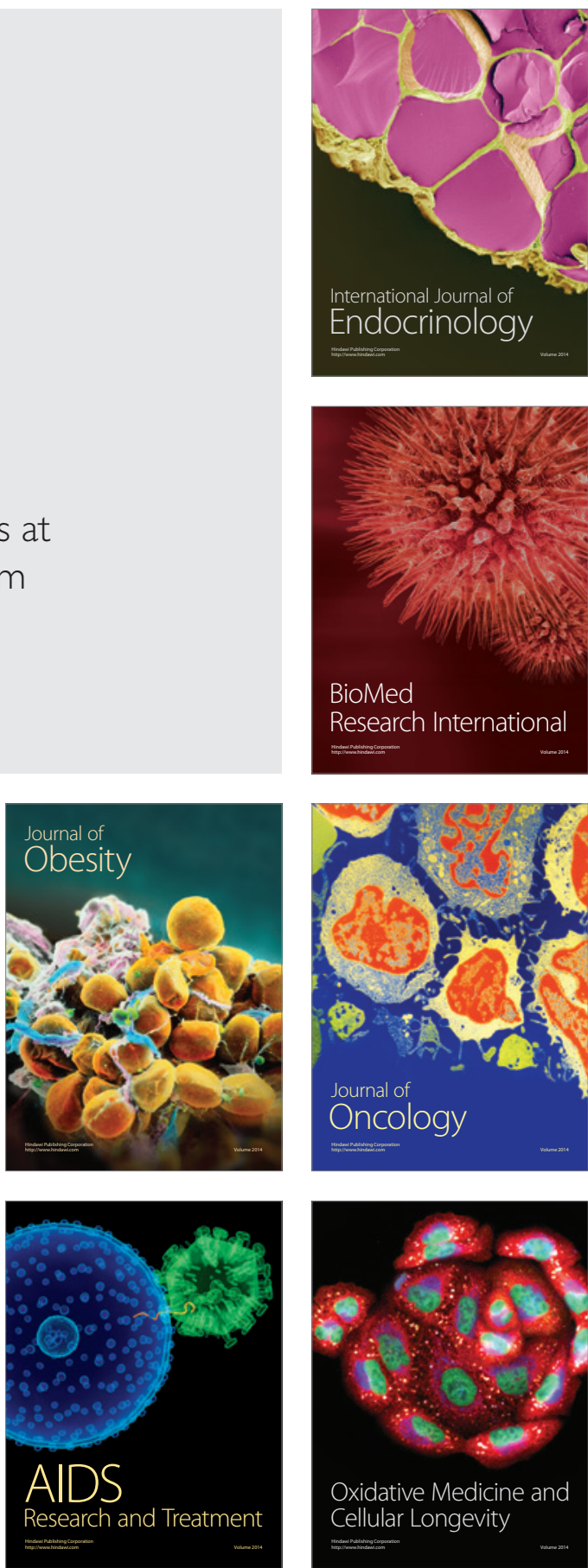